\title{
Study on the sensitivity of the vertical cooling (heat sink) on the displacements of the mid-tropospheric ridge using a linear model
}

\author{
A ChANDRASEKAR \\ Department of Physics and Meteorology, Indian Institute of Technology, Kharagpur 721 302, India
}

\begin{abstract}
A linear model of the response of a stratified atmosphere to isolated heat sources in spherical coordinates is used to study the maintenance of the mean position of the mid tropospheric ridge and its displacement. It is well known that the performance of the southwest Indian monsoon is related to the latitudinal position of the April $500 \mathrm{hPa}$ ridge along $75^{\circ} \mathrm{E}$. It was demonstrated that an anomalous cooling associated with the increased snow cover in Eurasia can result in moderate southward displacement of the mid-tropospheric ridge. The results of this study indicate that the vertically integrated cooling rate (strength of heat sink) has more effect on the southward displacement of the ridge when the sink is closer to the ridge.
\end{abstract}

\section{Introduction}

One of the most important features of the climatology over the Indian region is the existence of a mid-tropospheric ridge pattern at $500 \mathrm{hPa}$ over southern India and its latitudinal migration with seasons. The axis of the mid tropospheric ridge at $500 \mathrm{hPa}$ along $75^{\circ} \mathrm{E}$ is seen at $11.5^{\circ} \mathrm{N}$ during January, $15^{\circ} \mathrm{N}$ during April, $28^{\circ} \mathrm{N}$ during July and $20^{\circ} \mathrm{N}$ during October. Banerjee et al (1978) have shown that the mean latitudinal position of the above ridge during April is intimately related to the performance of the subsequent southwest Indian monsoon over the entire country. They showed that if the latitudinal position of the $500 \mathrm{hPa}$ ridge during April is south (north) of its normal position, rainfall over India for the subsequent southwest monsoon is mostly below (above) normal. Mooley et al (1986) have shown that the relationship between the April $500 \mathrm{hPa}$ ridge position and the southwest monsoon rainfall over India is highly significant and stable. Verma (1980) after examining the monthly mean anomalies of 300-100 hPa thickness for ten years (1968-1977) for selected stations over India, found that the anomalies in April and May tend to persist for the whole monsoon season and that negative (positive) thickness anomalies in the pre-monsoon months were associated with negative (positive) anomalies of the southwest Indian monsoon rainfall. The long persistence of thickness anomalies during April and May, may in turn be related to the amount of snow cover over Eurasia.

Many investigators have studied the relationship between the winter/spring snow cover over Eurasia and the subsequent Indian summer monsoon rainfall through observational (Hahn and Shukla 1976; Dey and Bhanukumar 1982; Blanford 1884; Bamzai and Shukla 1999) as well as modelling (Barnett et al 1989; Yasunari et al 1991; Vernekar et al 1995) studies and found an inverse relationship. All the above studies have shown that increased snow cover over Eurasia in winter/spring can cause a weaker Indian summer monsoon. Extensive snow cover over Eurasia in winter/spring, in addition to the albedo effect can also be responsible for significant reduction in the heating of the ground and hence of the atmosphere due to melting of the snow as well as moistening of the surface due to the melted snow. Bhanukumar (1988 a,b) has shown that the satellite derived January snow cover

Keywords. Eurasian snow cover; mid-tropospheric ridge; southwest Indian monsoon; normal modes; heat sources and heat sinks. 
over Eurasia is negatively related to the April $500 \mathrm{hPa}$ ridge position along $75^{\circ} \mathrm{E}$ and to the southwest Indian monsoon rainfall. Shukla and Mooley (1987) found a correlation coefficient of -0.49 between April $500 \mathrm{hPa}$ ridge location and December through March Eurasian snow cover.

Chandrasekar and Goswami (1996) used a linear beta plane model in their study of the displacement of the mid-tropospheric ridge. The effect of excessive winter and spring snow cover over Eurasia is that less solar energy is available to heat the atmosphere due to high albedo of snow. They modeled the anomalous cooling associated with the increased snow cover in Eurasia as a heat sink and prescribed the same to the north of the tropical heat sources. The introduction of the above sink resulted in significant displacement of the midtropospheric ridge. Chandrasekar (1997) extended the above problem by including a heat sink (which is nonvanishing at the surface) and obtained southward displacement of the ridge.

The first objective of this work is to study the displacement of the mid-tropospheric ridge using a linear model in spherical coordinates. A further and more important objective of this work is to study the sensitivity of the southward displacement of the mid-tropospheric ridge to the strength and latitudinal position of the heat sink.

\section{The model description}

We consider a stratified atmosphere on a sphere. The basic equations on a sphere are linearized about a basic state of rest with constant static stability. Damping is present in the form of Rayleigh friction $\left(\alpha_{R}\right)$ and Newtonian cooling $\left(\alpha_{T}\right)$. The linear equations on a sphere in log pressure vertical coordinates governing steady motion forced by heating are given by (Sashegyi and Geisler 1987).

$$
\begin{gathered}
\alpha_{R} u-2 \Omega y v=-\frac{1}{a} \frac{\partial \phi}{\partial \lambda} \\
\alpha_{R} v+2 \Omega y u=-\frac{\left(1-y^{2}\right)}{a} \frac{\partial \phi}{\partial y} \\
\frac{1}{a\left(1-y^{2}\right)} \frac{\partial u}{\partial \lambda}+\frac{1}{a} \frac{\partial v}{\partial y}+e^{Z / H} \frac{\partial\left(e^{-Z / H} w\right)}{\partial z}=0 \\
\alpha_{T} \frac{\partial \phi}{\partial z}+N^{2} w=\frac{R Q}{H c_{p}} \\
\frac{\partial \phi}{\partial z}=\frac{R T}{H}
\end{gathered}
$$

Here $z=-H \ln \frac{p}{p_{o}}, p$ is the pressure, $p_{o}$ is the reference pressure $(1000 \mathrm{hPa})$ and $H$ is the scale height $H=\frac{R T_{o}}{g}$. The scale height is assigned a value of $8.8 \mathrm{~km}$. The latitudinal coordinate $y=\sin \theta$ where $\theta$ is the latitude and $\lambda$ is the longitude in radians. $u$ and $v$ are the perturbation horizontal velocity components multiplied by $\cos \theta, w$ is the perturbation vertical velocity in the log pressure coordinates while $\phi$ and $T$ are the geopotential perturbation and temperature perturbation. We assume a constant static stability with $N^{2}=1.11 \times 10^{-4} \mathrm{~s}^{-2}$. A rigid lid is placed at a height of $D=22.5 \mathrm{~km}$ above the level of forcings (Sashegyi and Geisler 1987).

We introduce the variables $U, V, \Phi$ such that

$$
(u, v, \phi)=(U, V, \Phi) \exp \frac{z}{2 H}
$$

and eliminate the vertical velocity $w$ between (3) and (4) to get

$$
\begin{gathered}
\alpha_{R} U-2 \Omega y V=-\frac{1}{a} \frac{\partial \Phi}{\partial \lambda} \\
\alpha_{R} V+2 \Omega y U=-\frac{\left(1-y^{2}\right)}{a} \frac{\partial \Phi}{\partial y} \\
\frac{\alpha_{T}}{4 H^{2} N^{2}}\left(\frac{\partial^{2} \Phi}{\partial z^{2}}-\Phi\right)-\frac{1}{a\left(1-y^{2}\right)} \frac{\partial U}{\partial \lambda}-\frac{1}{a} \frac{\partial V}{\partial y} \\
=\frac{R A(\lambda, y) F(z)}{\tau N^{2} H^{2} c_{p}}
\end{gathered}
$$

where $F=\exp \left(\frac{-z}{2 H}\right)\left(H \frac{\partial B}{\partial z}-B\right)$ where the heating function $\mathrm{Q}$ has the form $Q(\lambda, y, z)=A(\lambda, y) B(z)$. The quantity $\tau$ in (9) is the length of the day in seconds and appears as we wish the unit of $\frac{Q}{c_{p}}$ to be ${ }^{\circ} \mathrm{C}$ day ${ }^{-1}$. We define the vertical normal modes by the equation

$$
\frac{\mathrm{d}^{2} G_{n}}{\mathrm{~d} z^{2}}+\left(\frac{N^{2}}{g h_{n}}-\frac{1}{4 H^{2}}\right) G_{n}
$$

and the boundary condition

$$
\frac{\mathrm{d} G_{n}}{\mathrm{~d} z}+\frac{G_{n}}{2 H}=0
$$

at the levels $z=0$ and $z=D$.

Expanding the solutions and the forcing on to the set of vertical modes gives the equations

$$
\begin{aligned}
& \alpha_{R} U_{n}-2 \Omega V_{n} \sin \theta=-\frac{1}{a} \frac{\partial \Phi_{n}}{\partial \lambda}, \\
& \alpha_{R} V_{n}+2 \Omega U_{n} \sin \theta=-\frac{\cos \theta}{a} \frac{\partial \Phi_{n}}{\partial \theta},
\end{aligned}
$$




$$
\begin{aligned}
\frac{\alpha_{T}}{g h_{n}} & \Phi_{n}+\frac{1}{a \cos ^{2} \theta} \frac{\partial U_{n}}{\partial \lambda}+\frac{1}{a \cos \theta} \frac{\partial V_{n}}{\partial \theta} \\
& =-\frac{R f_{n} A(\lambda, y)}{\tau N^{2} H^{2}}
\end{aligned}
$$

for the coefficients in this expansion. The amplitude $f_{n}$ of the projection of the forcing function $F$ on the $n$th mode is

$$
f_{n}=\frac{\int_{0}^{D} F(z) G_{n}(z) \mathrm{d} z}{\int_{0}^{D} G_{n}^{2} \mathrm{~d} z} .
$$

The solution of (10) and (11) consists of the external mode

$$
G_{o}(z)=\exp \left(-\frac{z}{2 H}\right)
$$

and the internal mode

$$
G_{n}(z)=\sin \left(\frac{n \pi z}{D}-\Theta_{n}\right),
$$

where $n$ is a positive integer and

$$
\Theta_{n}=\tan ^{-1}\left(\frac{2 n \pi H}{D}\right) .
$$

The equivalent depth $h_{o}$ for the external mode is infinite while the same for the internal modes are given by

$$
h_{n}=\left(\frac{N^{2} H^{2}}{g}\right)\left[0.25+\left(\frac{n \pi H}{D}\right)^{2}\right]^{-1}
$$

With a depth $D=22.5 \mathrm{~km}$, the first six internal modes have equivalent depths of $498,140,63,36$, 23 and $16 \mathrm{~m}$, respectively.

\section{Description of heat sources}

As in Chandrasekar and Goswami (1996), we first simulate the mid tropospheric anticyclone by prescribing two noncircular heat sources centered at $\left(60^{\circ} \mathrm{E}, 13^{\circ} \mathrm{N}\right)$ and $\left(90^{\circ} \mathrm{E}, 13^{\circ} \mathrm{N}\right)$, respectively. The heating function for a single source is defined as $Q(\lambda, \theta, z)=A(\lambda, \theta) B(z)$ where

$$
A(\lambda, \theta)=\exp \left[-\frac{\left(\lambda-\lambda_{o}\right)^{2}}{\lambda_{w}^{2}}-\frac{\left(\theta-\theta_{o}\right)^{2}}{\theta_{w}^{2}}\right],
$$

where $\left(\lambda_{o}, \theta_{o}\right)$ is the center of the heat source, $\lambda_{w}=8^{\circ}$ and $\theta_{w}=5^{\circ}$ are the $e$ folding distances in longitude and latitude. The vertical dependence $B(z)$ is defined as

$$
\begin{array}{cl}
0 & , z \geq z_{U} \\
B(z)=a \sin (\pi \eta) \exp ^{-b \eta} & , z_{L}<z<z_{U} \\
0 & , z \leq z_{L}
\end{array}
$$

where $\eta=\frac{\left(p-p_{U}\right)}{\left(p_{L}-p_{U}\right)}, p_{L}$ and $p_{U}$ were chosen as $1000 \mathrm{hPa}$ and $100 \mathrm{hPa}$ and $z_{L}$ and $z_{U}$ are the $z$ values corresponding to $p_{L}$ and $p_{U} . b$ is a parameter which determines the shape of the vertical heating field. $b=0$ corresponds to a symmetric heating field while $b$ positive (negative) corresponds to maximum of heating in the upper (lower) troposphere. $a$ has been chosen such that $\frac{B(z)}{c_{p}}$ vertically averaged over the entire atmospheric column corresponds to a heating of $3^{\circ} \mathrm{C}$ day ${ }^{-1}$. For all the heat sources used in this study a symmetric heating field $(b=0)$ is assumed. The heat sources have maximum heating in the mid troposphere due to release of latent heat of condensation.

The equations (12) to (14) are solved for each of the first six internal modes and the solution variables are summed over these modes. The domain is limited to the following $30^{\circ} \mathrm{E} \leq \lambda \leq 120^{\circ} \mathrm{E}$ and $20^{\circ} \mathrm{S} \leq \theta \leq 70^{\circ} \mathrm{N}$ with $\Delta \lambda=2^{\circ}$ and $\Delta \theta=0.75^{\circ}$. $\alpha_{R}$ and $\alpha_{T}$ were assigned values $\left(\alpha_{R}^{-1}=\alpha_{T}^{-1}=\right.$ 5 days). We have used the same values for the coefficients of Rayleigh friction and Newtonian cooling as used by Sashegyi and Geisler (1987) in their study of cross equatorial flow forced by summer monsoon heat sources. The perturbation horizontal wind components were eliminated in equations (12) to (14) and the equation for the perturbation geopotential field was solved by the procedure as proposed by Lindzen and Kuo (1969). The boundary conditions for $\Phi_{n}$ were assigned zero values in the northern and southern boundaries and normal derivatives of $\Phi_{n}$ were assigned zero values in the eastern and western boundaries. The perturbation wind components were then obtained from the perturbation geopotential field.

\section{Results}

Figure 1 presents the geopotential perturbation field and the perturbation horizontal wind field at $500 \mathrm{hPa}$ for the case of two noncircular sources centered at $\left(60^{\circ} \mathrm{E}, 13^{\circ} \mathrm{N}\right)$ and $\left(90^{\circ} \mathrm{E}, 13^{\circ} \mathrm{N}\right)$. The figure clearly reveals a high centered north west of each of the heating centers. The winds are stronger to the south of the heating center with maximum wind speed of $7 \mathrm{~m} \mathrm{sec}{ }^{-1}$. In order that the heat sink correctly represents the Eurasian snow cover, the former is assigned the following 


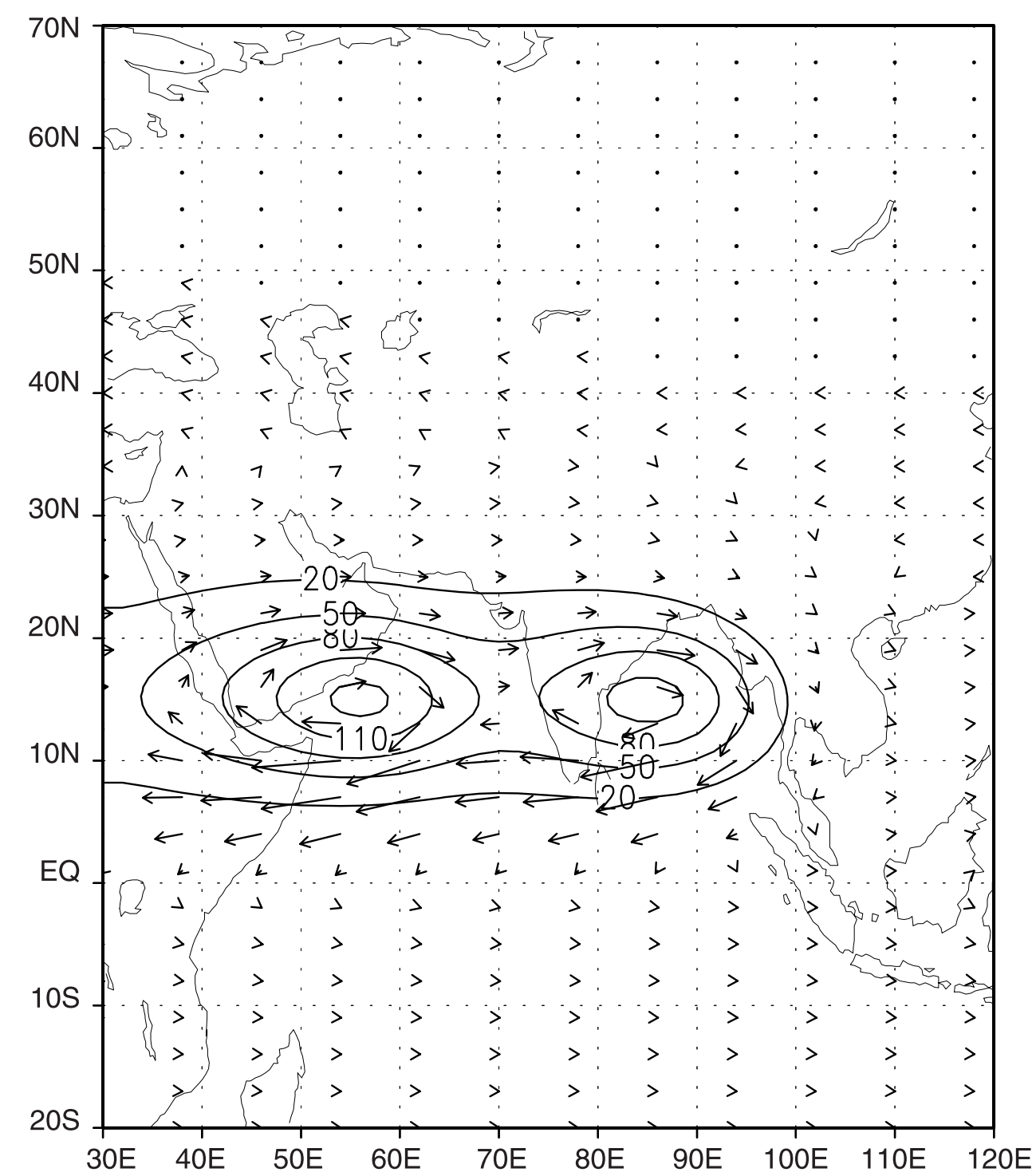

Figure 1. Geopotential perturbation field and the horizontal wind component perturbation field (in $\mathrm{msec}^{-1}$ ) at $500 \mathrm{hPa}$ for the case of two heat sources centered at $\left(60^{\circ} \mathrm{E}, 13^{\circ} \mathrm{N}\right)$ and $\left(90^{\circ} \mathrm{E}, 13^{\circ} \mathrm{N}\right)$. Contour values for the geopotential perturbation field (in $\mathrm{m}^{2} \mathrm{sec}^{-2}$ ) are $140,110,80,50$ and 20 . The vertically integrated heating rate is $3^{\circ} \mathrm{C} \mathrm{day}^{-1}$ and the $e$ folding distance of the heat source is $8^{\circ}$ in longitude and $5^{\circ}$ in latitude.

features. It is circular in shape and quite extensive in the horizontal with an $e$ folding distance of $22^{\circ}$. The sink is centered at $\left(60^{\circ} \mathrm{E}, 40^{\circ} \mathrm{N}\right)$. The vertical structure of the heat sink has maximum cooling in the lower troposphere $(b=-3)$ due to enhanced snow cover. Also the vertically averaged cooling rate over the entire atmospheric column is assumed to be $-2^{\circ} \mathrm{Cday}^{-1}$. Figure 2 depicts the geopotential perturbation field and the horizontal wind perturbation field at $500 \mathrm{hPa}$ after inclusion of the above heat sink. Figure 2 clearly reveals that the prescription of the above realistic heat sink has caused a southward displacement of the mid-tropospheric ridge at $500 \mathrm{hPa}$ by $290 \mathrm{~km}$. Figure 2 also reveals a cyclonic circulation over the region of the heat sink at $500 \mathrm{hPa}$. It is clearly seen that the horizontal wind speed has strength- ened in figure 2 and now has a maximum wind speed of $9 \mathrm{msec}^{-1}$. The westerlies forming the anticyclonic circulation to the north of the heat source are reinforced by the strong westerlies which form part of the cyclonic circulation, south of the heat sink.

Figures 3 and 4 provide the vertical structure of the heat source and the heat sink as used in figures 1 and 2 . The heating associated with the heat source is symmetric with the maximum heating in $500 \mathrm{hPa}$ with a value of $5.5^{\circ} \mathrm{C}_{\text {day }}{ }^{-1}$. The cooling associated with the heat sink is asymmetric with the maximum cooling in $800 \mathrm{hPa}$ (lower troposphere) with a value of $-5.8^{\circ} \mathrm{C}$ day $^{-1}$.

After obtaining significant southward displacement of the mid-tropospheric ridge, we conducted 


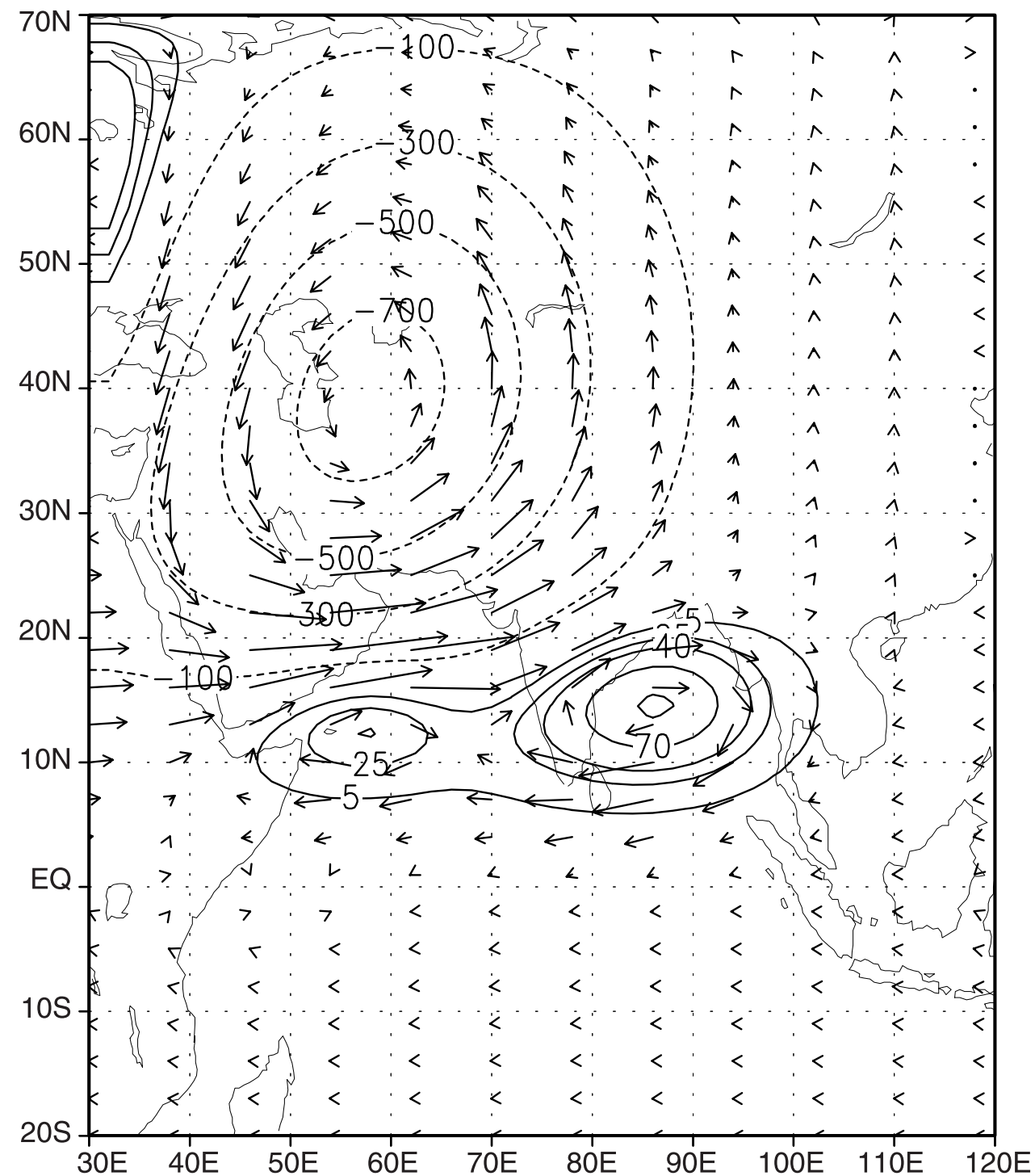

Figure 2. Geopotential perturbation field and the horizontal wind component perturbation field (in $\mathrm{m} \mathrm{sec}-1)$ at $500 \mathrm{hPa}$ for the case of two sources and a sink, the latter centered at $\left(60^{\circ} \mathrm{E}, 40^{\circ} \mathrm{N}\right)$ and having a vertically integrated cooling rate of $-2^{\circ} \mathrm{C}$ day ${ }^{-1}$ and an $e$ folding distance of $22^{\circ}$. Contour values for the geopotential perturbation field (in $\mathrm{m}^{2} \mathrm{sec}^{-2}$ ) are $-700,-500,-300,-100,5,25,40,70$ and 100.

a series of experiments to study the sensitivity of the vertical cooling (strength of the heat sink) and the latitudinal position of the heat sink to the southward displacement of the mid-tropospheric ridge over India. The following latitudinal positions $\left(34^{\circ} \mathrm{N}, 40^{\circ} \mathrm{N}, 46^{\circ} \mathrm{N}\right)$ and the following strengths of the sink (vertically integrated cooling rate $-2^{\circ} \mathrm{C}$ day $^{-1},-1.5^{\circ} \mathrm{C}$ day $^{-1},-1^{\circ} \mathrm{C}$ day $^{-1}$ ) are utilized in this study. For each of the above experiments the solution is summed over the first six internal modes. Figures 5 and 6 provide the vertical structure of the heat sink corresponding to a vertically integrated cooling rate of $-1.5^{\circ} \mathrm{C}$ day $^{-1}$ and $-1^{\circ} \mathrm{C}$ day $^{-1}$. Again the cooling associated with the heat sink is asymmetric with the maximum cooling in $800 \mathrm{hPa}$ with a value of $-4.4^{\circ} \mathrm{C}$ day $^{-1}$ (figure 5) and $-2.9^{\circ} \mathrm{C}_{\text {day }}{ }^{-1}$ (figure 6).
Figures 7 and 8 show the perturbation geopotential field and the horizontal wind perturbation field at $500 \mathrm{hPa}$ for the case of $-2^{\circ} \mathrm{C}$ day ${ }^{-1}$ for the heat sink centered at $34^{\circ} \mathrm{N}$ (figure 7 ) and $46^{\circ} \mathrm{N}$ (figure 8). Figures 7 and 8 reveal that the midtropospheric ridge has been displaced southwards by $500 \mathrm{~km}$ and $125 \mathrm{~km}$, respectively. It is clear from figures 2,7 and 8 that the latitudinal position of the center of the heat sink has a strong effect on the southward displacement of the midtropospheric ridge with maximum southward displacement observed for the case where the heat sink is closer. One would expect that the westerlies to the north of the heat source will be very strongly reinforced (moderately reinforced) by the strong westerlies forming south of the heat sink when the center of the heat sink is at a lower (higher) lati- 


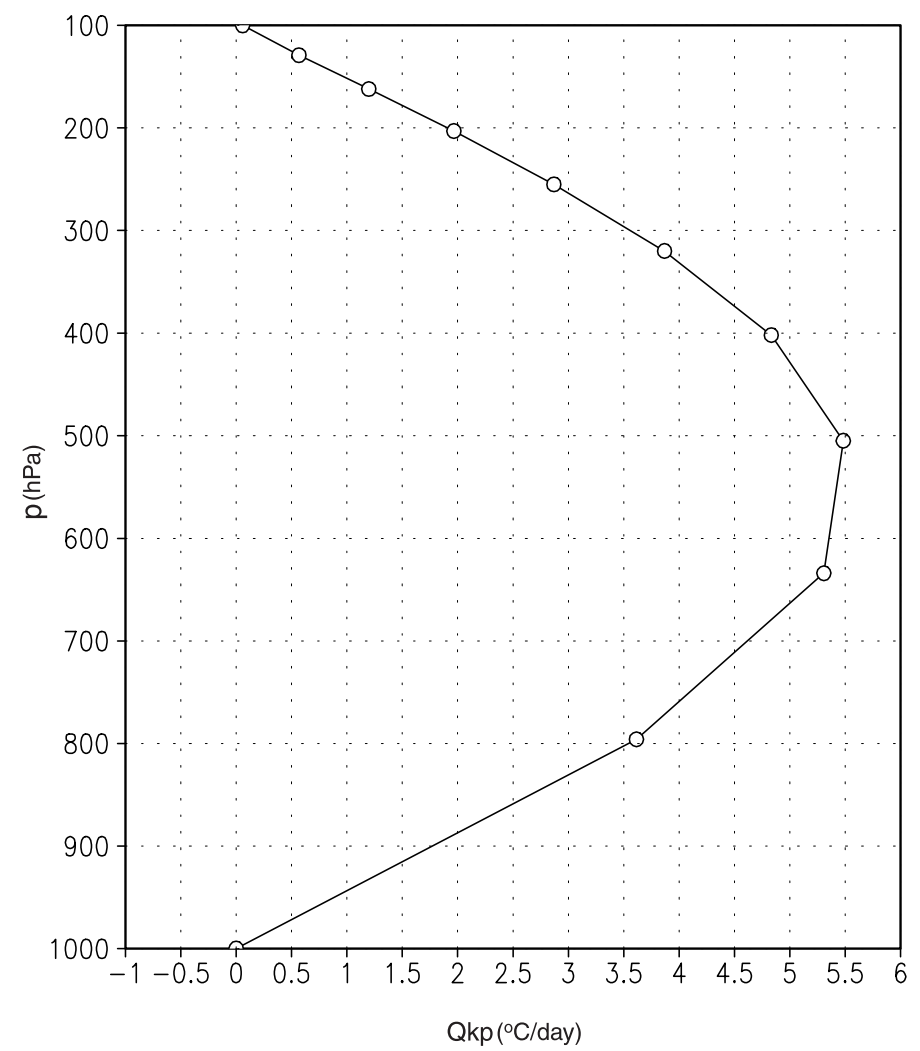

Figure 3. Vertical profile of the heat source with a vertically averaged heating rate of $3^{\circ} \mathrm{C} \mathrm{day}^{-1}$.

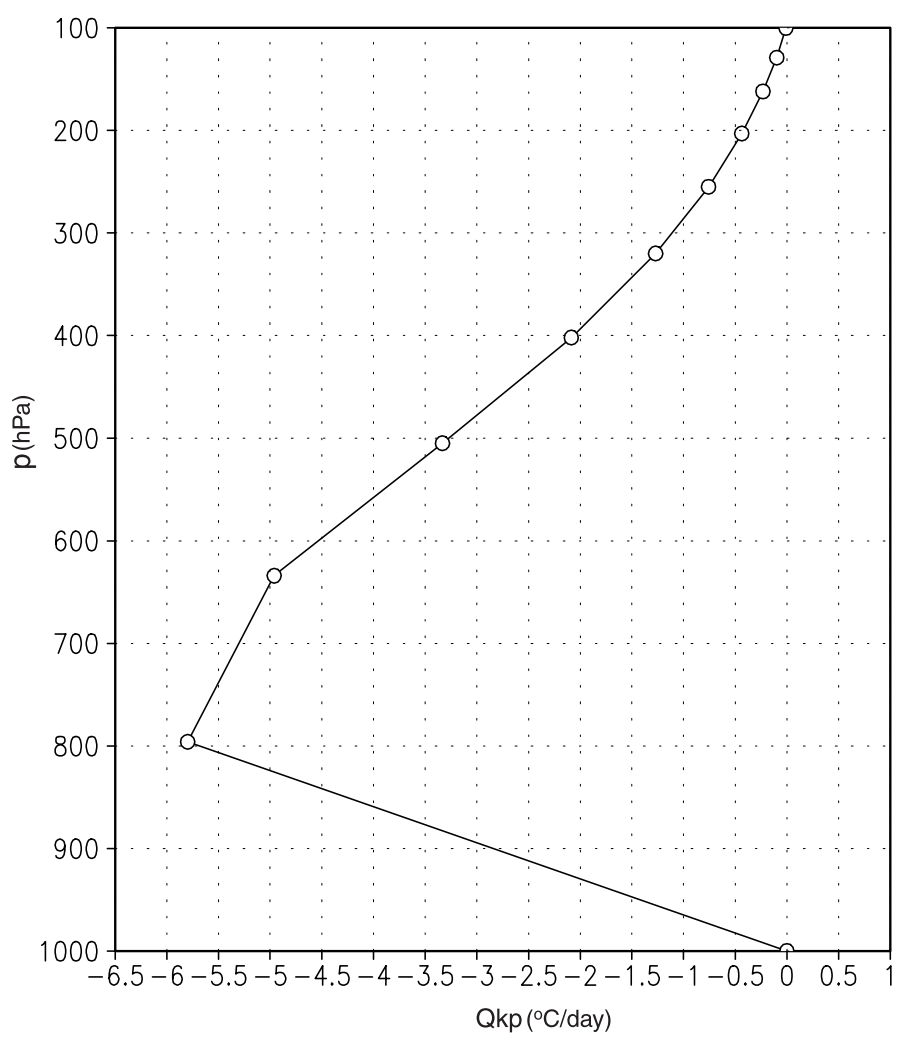

Figure 4. Vertical profile of the heat sink with a vertically averaged cooling rate of $-2^{\circ} \mathrm{C}$ day ${ }^{-1}$. 


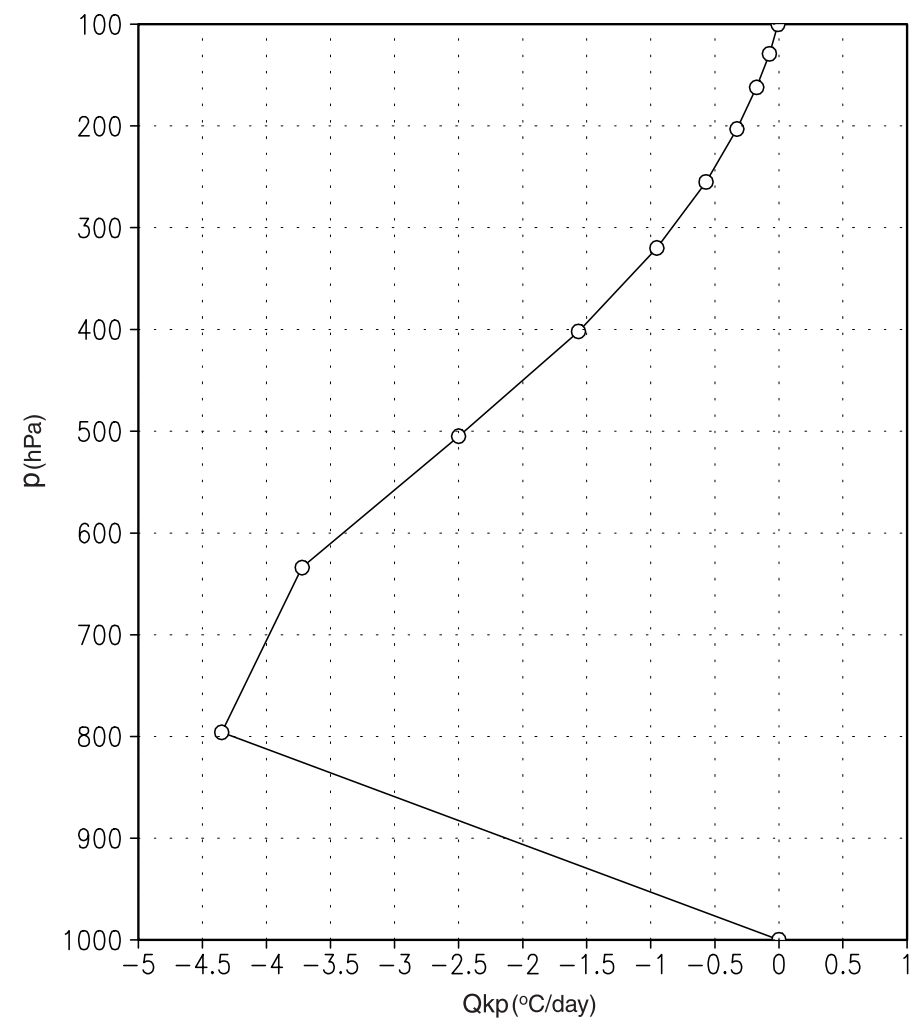

Figure 5. Vertical profile of the heat sink with a vertically averaged cooling rate of $-1.5^{\circ} \mathrm{C}$ day $^{-1}$.

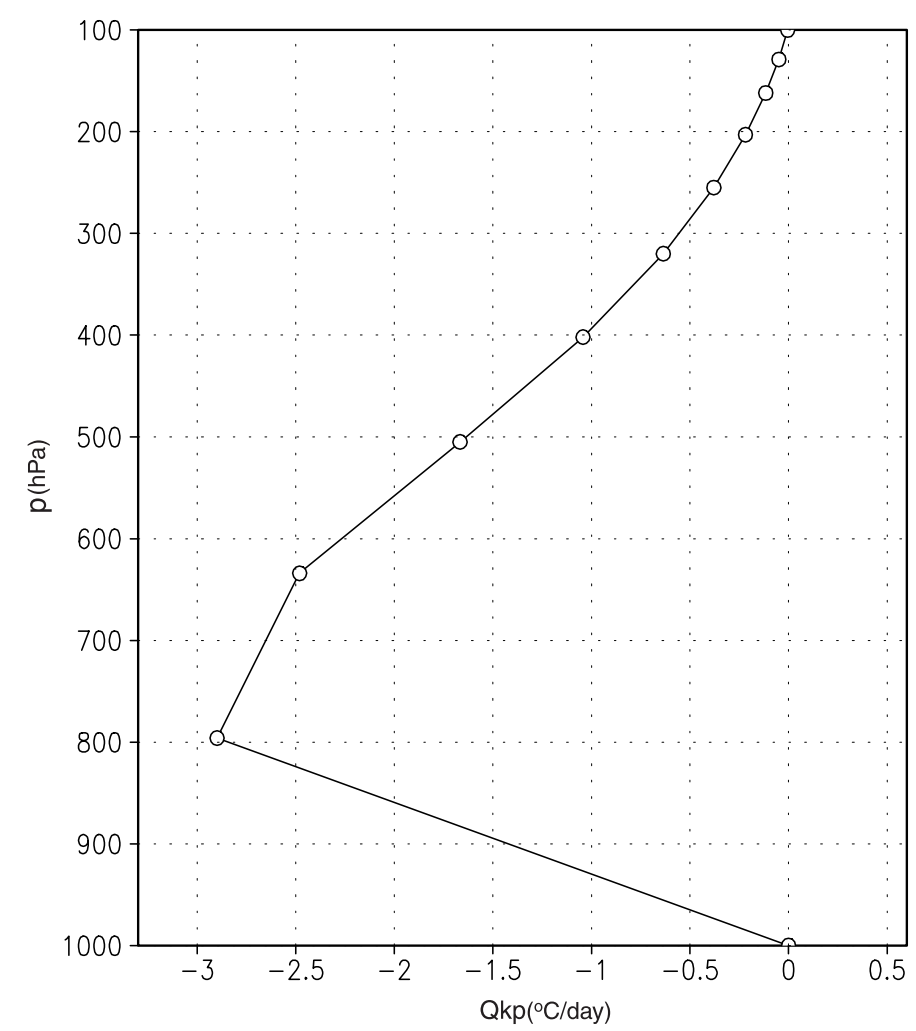

Figure 6. Vertical profile of the heat sink with a vertically averaged cooling rate of $-1^{\circ} \mathrm{C}$ day ${ }^{-1}$. 


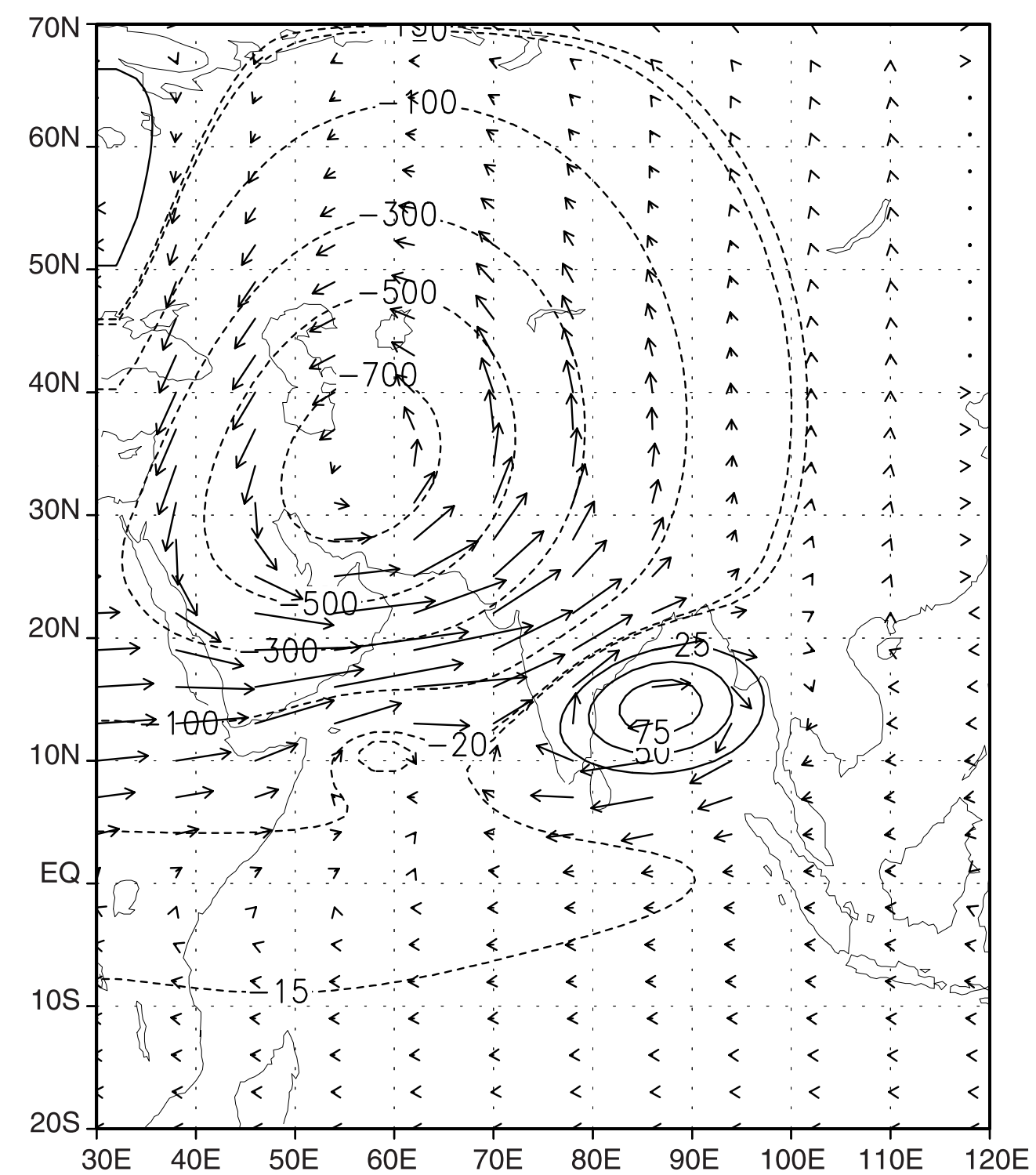

Figure 7. Same as figure 2 except that the heat sink is centered at $\left(60^{\circ} \mathrm{E}, 34^{\circ} \mathrm{N}\right)$. Contour values of the geopotential perturbation field (in $\mathrm{m}^{2} \mathrm{sec}^{-2}$ ) are $-700,-500,-300,-100,-20,-15,25,50$ and 75 .

tude. This is obvious in figures 7 and 8 with maximum wind speed of $11 \mathrm{~m} \mathrm{sec}^{-1}$ and $7 \mathrm{~m} \mathrm{sec}^{-1}$, respectively.

In order to bring out the effect of the sensitivity of the vertical cooling of the heat sink on the southward displacement of the mid-tropospheric ridge, we present figures 9 and 10. The position of the center of the heat sink is the same $\left(46^{\circ}\right)$ in both the figures. While figure 9 provides the perturbation geopotential field and the horizontal wind perturbation field at $500 \mathrm{hPa}$ for the case of $-1.5^{\circ} \mathrm{C}$ day $^{-1}$, figure 10 provides the same for the case of $-1{ }^{\circ} \mathrm{C}$ day $^{-1}$. Figures 9 and 10 reveal a weaker low centered over the region of the heat sink as compared to figure 8. Figures 9 and 10 reveal that the mid-tropospheric ridge has displaced southward by $125 \mathrm{~km}$ and $83 \mathrm{~km}$, respectively. The above result provides evi- dence that a stronger heat sink (increased snow cover over Eurasia) can cause increased southward displacement of the mid-tropospheric ridge. The maximum wind speed in figures 9 and 10 is $6 \mathrm{~m} \mathrm{sec}^{-1}$.

Figures 11 and 12 show the perturbation geopotential field and the horizontal wind perturbation field at $500 \mathrm{hPa}$ for the cases where the heat sink is centered at $34^{\circ} \mathrm{N}$ and $40^{\circ} \mathrm{N}$, respectively. Both the above figures correspond to a cooling rate of $-1.5^{\circ} \mathrm{C}$ day $^{-1}$. Figures 11 and 12 reveal that the mid-tropospheric ridge has displaced southward by $374 \mathrm{~km}$ and $208 \mathrm{~km}$. As expected the maximum wind speed is stronger in figure $11\left(9 \mathrm{~m} \mathrm{sec}^{-1}\right)$ and in figure $12\left(7 \mathrm{~m} \mathrm{sec}^{-1}\right)$ as compared with figure 9 .

Figures 13 and 14 show the perturbation geopotential field and the horizontal wind perturbation field at $500 \mathrm{hPa}$ for the cases where the heat sink 


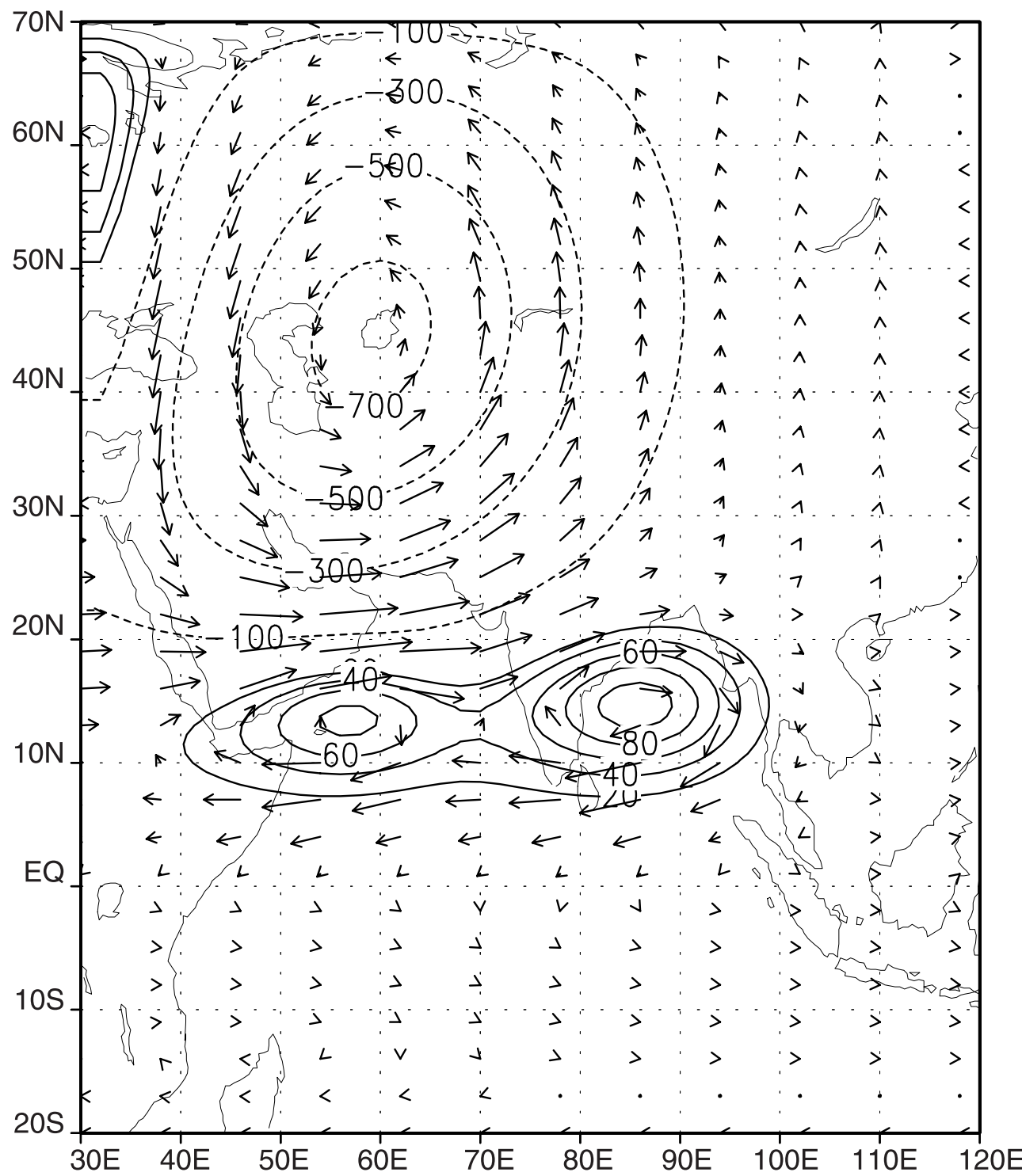

Figure 8. Same as figure 2 except that the heat sink is centered at $\left(60^{\circ} \mathrm{E}, 46^{\circ} \mathrm{N}\right)$. Contour values of the geopotential perturbation field $\left(\right.$ in $\mathrm{m}^{2} \mathrm{sec}^{-2}$ ) are $-700,-500,-300,-100,20,40,60,80$ and 100.

is centered at $34^{\circ} \mathrm{N}$ and $40^{\circ} \mathrm{N}$, respectively. Both the above figures correspond to a cooling rate of $-1^{\circ} \mathrm{C}$ day $^{-1}$. Figures 13 and 14 reveal that the mid-tropospheric ridge has displaced southward by $208 \mathrm{~km}$ and $125 \mathrm{~km}$.

The horizontal extent of the heat sink in all the above experiments were the same ( $e$ folding distance of $22^{\circ}$ ). We performed one experiment with smaller horizontal extent of the heat sink ( $e$ folding distance of $12^{\circ}$ ). The center of the heat sink was kept at $\left(60^{\circ} \mathrm{E}, 40^{\circ} \mathrm{N}\right)$ and the vertically averaged cooling rate was $-2^{\circ} \mathrm{C}$ day ${ }^{-1}$. The mid-tropospheric ridge was displaced southward by $41 \mathrm{~km}$. We have not shown the perturbation geopotential field and the perturbation horizontal wind field at $500 \mathrm{hPa}$ for the above case for brevity.
The results of the sensitivity study on the vertical cooling and the position of the heat sink on the southward displacement of the mid-tropospheric ridge at $500 \mathrm{hPa}$ are provided in table 1 . The results of the sensitivity study indicate that the vertically integrated cooling rate (strength of sink) has more effect on the southward displacement of the $500 \mathrm{hPa}$ ridge when the sink is centered at the lower latitude $\left(34^{\circ} \mathrm{N}\right)$. The latitudinal position of the center of the sink, in turn has an important effect on the displacement of the $500 \mathrm{hPa}$ ridge when the sink is strong (vertically integrated cooling rate of $2{ }^{\circ} \mathrm{C}$ day $\left.^{-1}\right)$.

Previous investigators after studying the relationship between the winter and spring snow cover over Eurasia and the April $500 \mathrm{hPa}$ ridge over India found that an increased snow cover over Eura- 


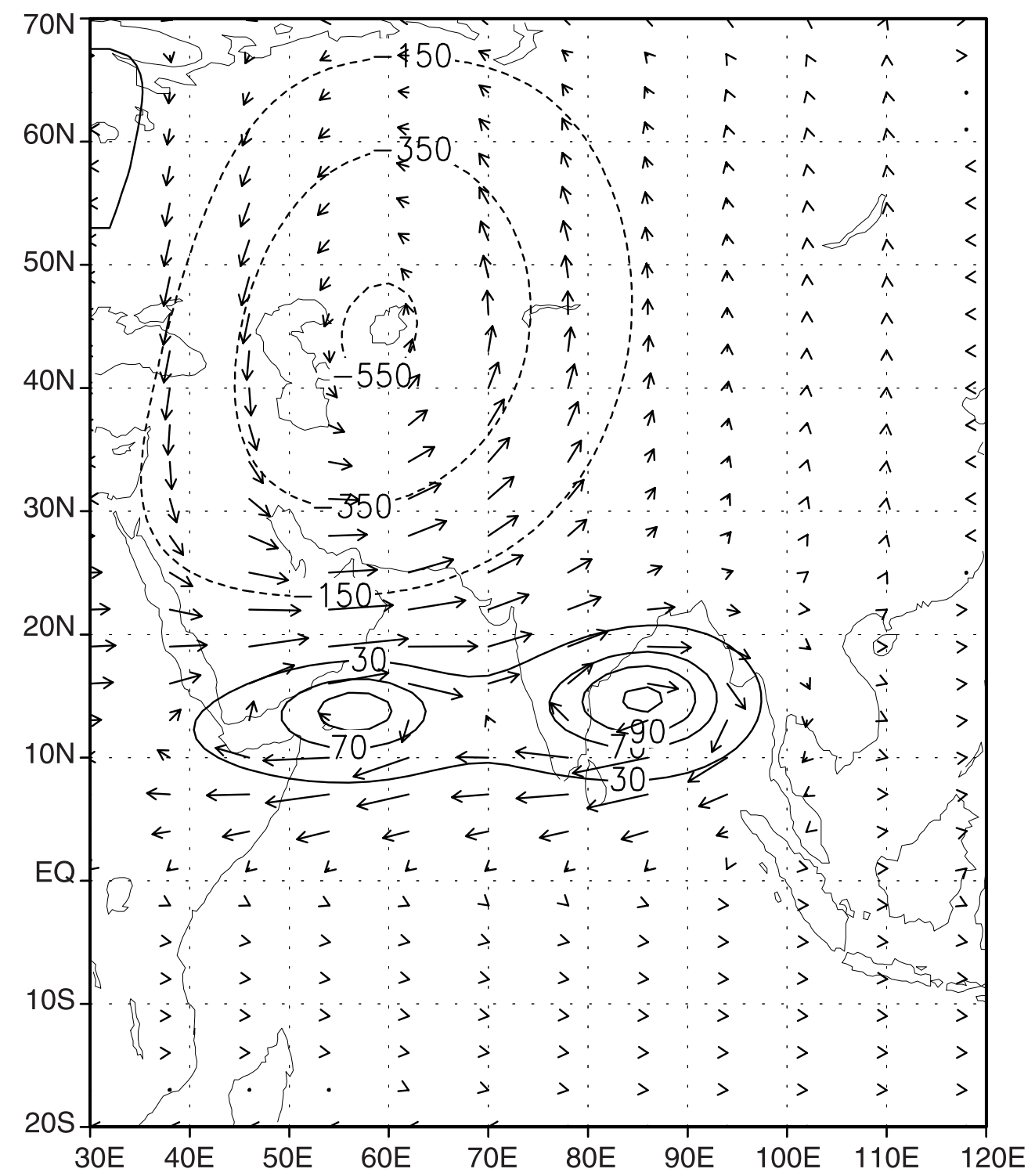

Figure 9. Same as figure 8 except that the heat sink has a vertically integrated cooling rate of $-1.5^{\circ} \mathrm{C} \mathrm{day}{ }^{-1}$. Contour values of the geopotential perturbation field $\left(\mathrm{in} \mathrm{m}^{2} \mathrm{sec}^{-2}\right.$ ) are $-550,-350,-150,30,70,90$ and 110 .

sia in the preceding winter/spring caused a southward displacement of the mid-tropospheric ridge from its normal April position. Extensive snow cover over Eurasia in winter/spring, in addition to the albedo effect can also be responsible for significant reduction in the heating of the ground and hence of the atmosphere due to melting of the snow as well as moistening of the surface due to the melted snow. Hence the above can invariably lead to a much colder troposphere in April.

While summer conditions begin to be established in the lower troposphere over peninsular India in March, winter circulation prevails over north India until the beginning of May. The circulation over north and central India during winter becomes westerly due to the southward shift of the extra-tropical westerly belt. Also north and central India in winter come under the influence of the so-called western disturbance which is manifested by the passage of deep lows or troughs. In the rear of these disturbances in the westerlies, very cold air from higher latitudes flows in over north and central India. The mid-tropospheric ridge demarcates the westerly circulatory regime of the north from the easterly tropical regime to the south. Hence the latitudinal position of the $500 \mathrm{hPa}$ ridge is a measure of the influence exerted by the troughs in the westerlies on the upper tropospheric thermal conditions over north and central India (Mooley et al 1986). Hence atmospheric conditions corresponding to a much colder troposphere over north and central India in April should be associated with a marked southward displacement of the $500 \mathrm{hPa}$ ridge. From the above, the physical basis for the relationship between the 


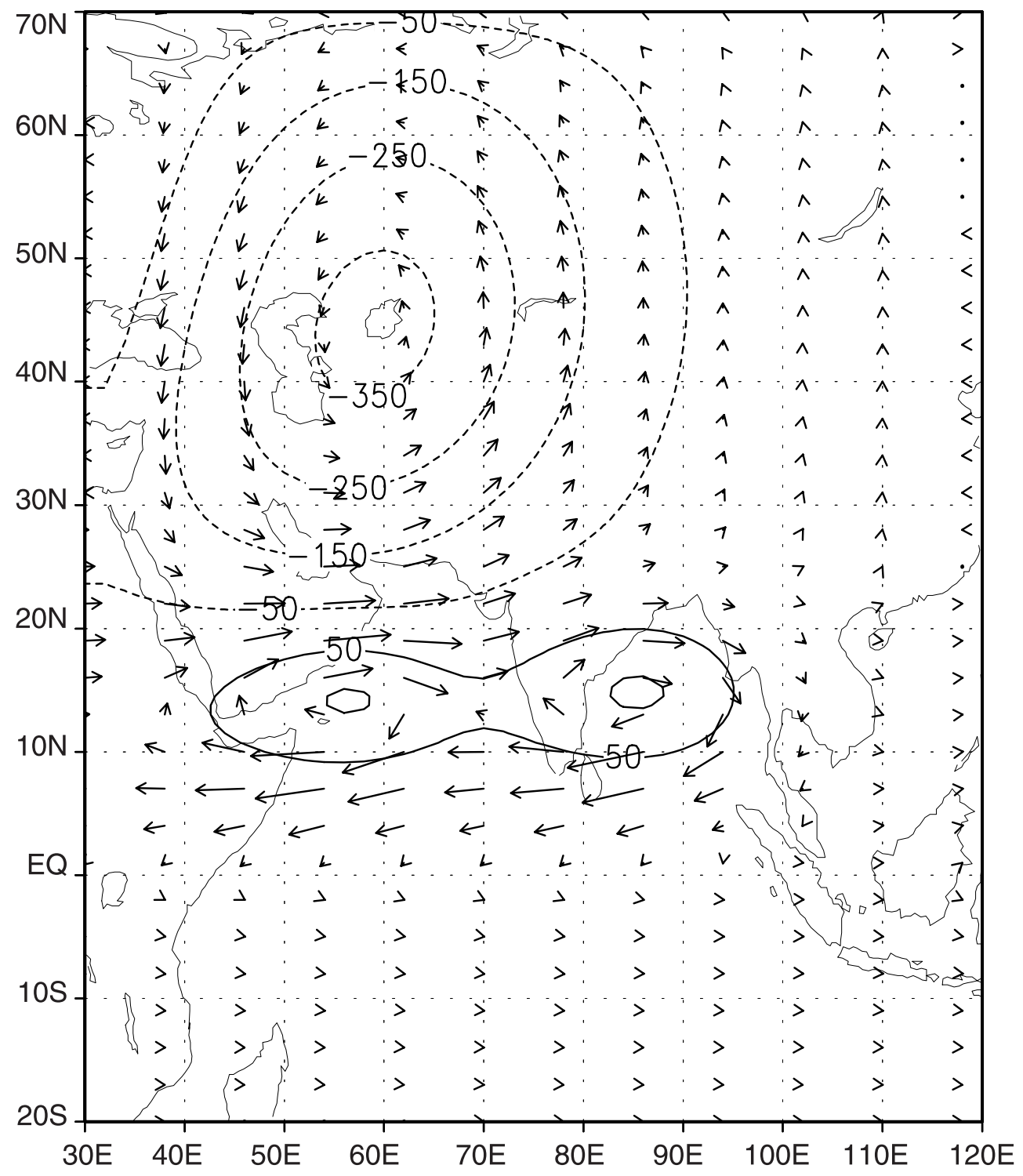

Figure 10. Same as figure 8 except that the heat sink has a vertically integrated cooling rate of $-1^{\circ} \mathrm{C}$ day ${ }^{-1}$. Contour values of the geopotential perturbation field (in $\mathrm{m}^{2} \mathrm{sec}^{-2}$ ) are $-350,-250,-150,-50,50$ and 110 .

increased snow cover over Eurasia and the latitudinal position of the $500 \mathrm{hPa}$ ridge is clear. Also the above places the present study in the context of the general circulation over north and central India.

Chandrasekar and Goswami (1996) utilized a linear model in a beta plane and investigated the southward displacement of the $500 \mathrm{hPa}$ ridge. They obtained moderate southward displacement $(123 \mathrm{~km})$ of the $500 \mathrm{hPa}$ ridge in their study. In this study we have obtained significant southward displacement of the $500 \mathrm{hPa}$ ridge by as much as $500 \mathrm{~km}$. Although there are differences (other than that of the $\beta$ plane and the spherical coordinate system) like differences in the horizontal resolution $(\Delta x=123 \mathrm{~km}$ and $\Delta y=61.5 \mathrm{~km}$ in the $\beta$ plane case and $\Delta \lambda=2^{\circ}$ and $\Delta \theta=$ $0.75^{\circ}$ in the present study) and small differences in the damping coefficients $\left((4 \text { days })^{-1}\right.$ in the $\beta$ plane case and $(5 \text { days })^{-1}$ in the present study), we feel the differences in the southward displacement of the $500 \mathrm{hPa}$ ridge between the earlier and the present study are due to the following reasons.

In the earlier investigation involving $\beta$ plane, we had utilized a solution procedure involving relaxation type which was iterative in nature. In the present study we have utilized a solution procedure proposed by Lindzen and Kuo (1969) which is based on direct matrix inversion. In the earlier study the geopotential perturbation field for the case of heat source with a vertically integrated heating rate of $3^{\circ} \mathrm{C}$ day $^{-1}$ yielded a maximum value of $220 \mathrm{~m}^{2} \mathrm{sec}^{-2}$ and the same for a heat sink with 


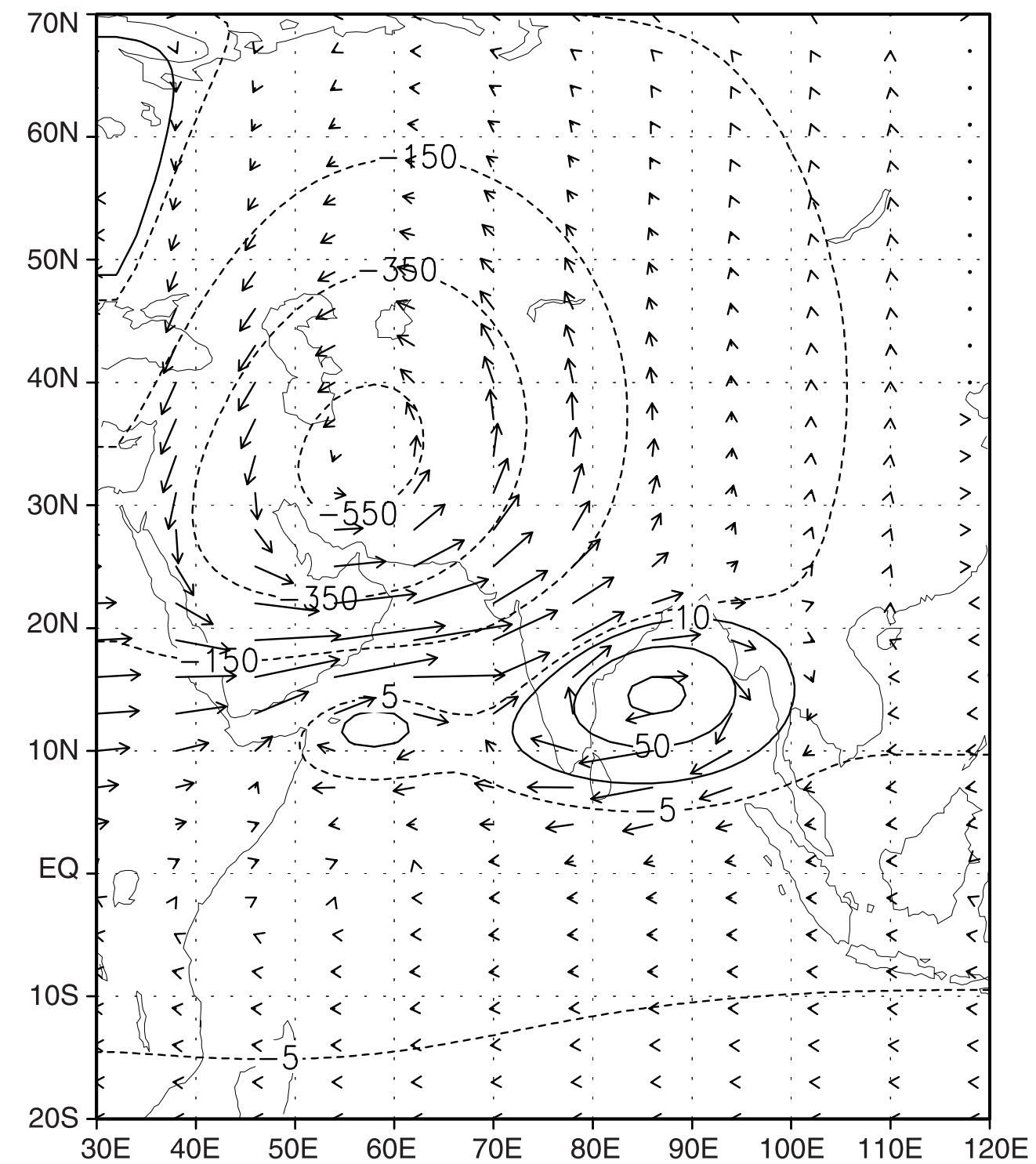

Figure 11. Same as figure 9 except that the heat sink is centered at $\left(60^{\circ} \mathrm{E}, 34^{\circ} \mathrm{N}\right)$. Contour values of the geopotential perturbation field (in $\mathrm{m}^{2} \mathrm{sec}^{-2}$ ) are $-550,-350,-150,-5,10,50$ and 90 .

a vertically integrated cooling rate of $-2^{\circ} \mathrm{C} \mathrm{day}^{-1}$ yielded a maximum negative value of $-875 \mathrm{~m}^{2}$ $\mathrm{sec}^{-2}$. In the present study the geopotential perturbation field although of the same order has yielded geopotential perturbation field of a maximum value $140 \mathrm{~m}^{2} \mathrm{sec}^{-2}$ for the heat source and a maximum negative value of $-700 \mathrm{~m}^{2} \mathrm{sec}^{-2}$. Although there is a basic difference in the horizontal coordinate system (from the $\beta$ plane and the present study), the differences could also be partly attributed to the different solution procedures.

The southward displacement of the $500 \mathrm{hPa}$ ridge is estimated from the geopotential perturbation field (i.e., displacement of the center of the highs for the case of two sources and for the case where the sink is introduced). In the present study all the figures were plotted using GrADS. There is a provision in the above display system to view the grid point values of any scalar field. We have utilised the above to look at the grid point values of the geopotential perturbation field. When we have the situation where the same maximum geopotential perturbation value is found at two adjacent latitudinal grid points, we have assumed that the high is centered at the mid-latitude of the two neighbouring latitudinal grid points. For cases where neighbouring three latitudinal grid points have the same maximum value of geopotential perturbation field we have assumed that the high is at the central latitude. In the earlier $\beta$ plane study (for the above situation) we considered the high to be at the lower latitude grid point. Hence in the earlier $\beta$ plane study we had sort of underestimated the southward displacement of the $500 \mathrm{hPa}$ ridge.

Our main objective in this study is to study the southward displacement of the $500 \mathrm{hPa}$ ridge over 


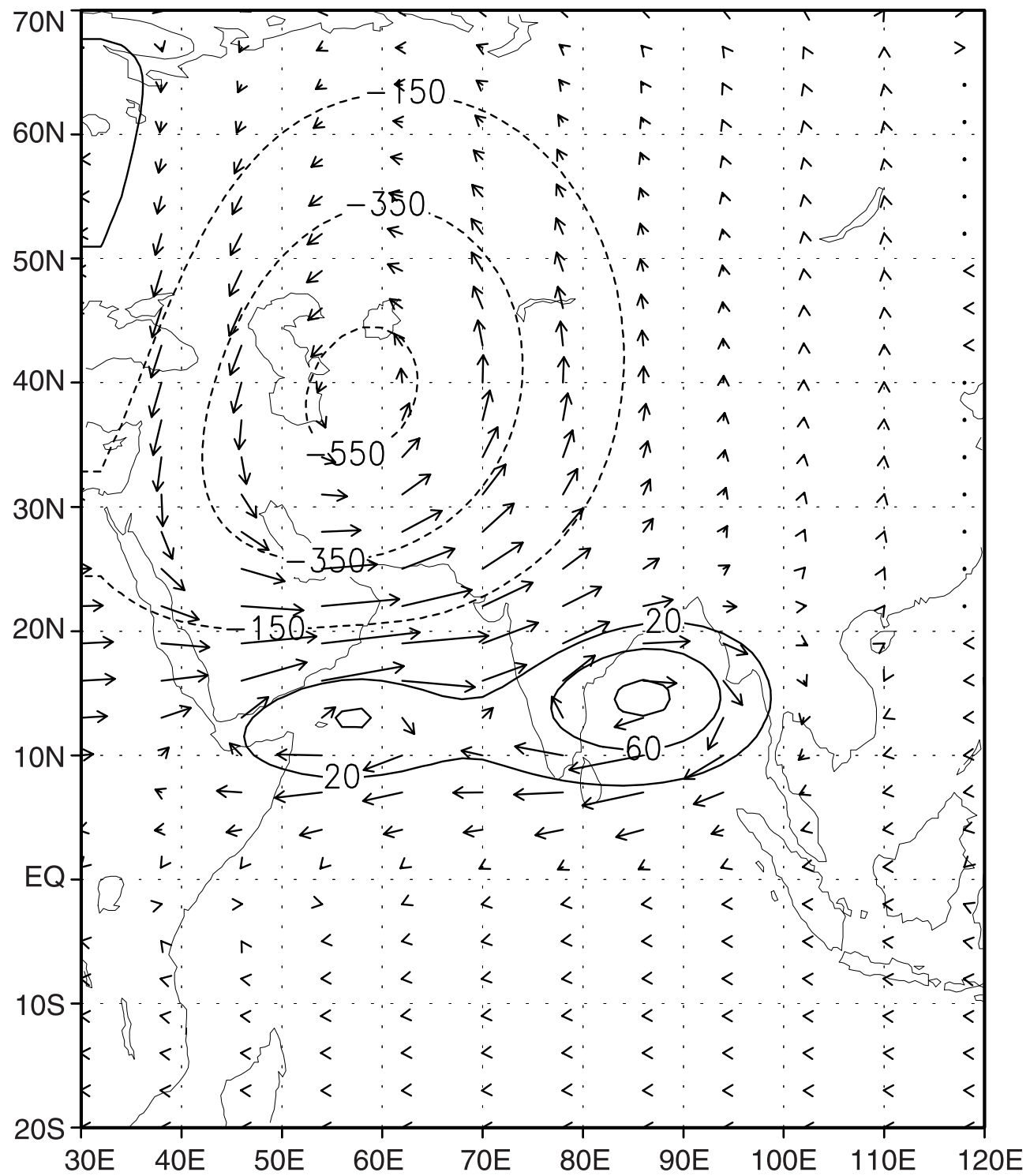

Figure 12. Same as figure 11 except that the heat sink is centered at $\left(60^{\circ} \mathrm{E}, 40^{\circ} \mathrm{N}\right)$. Contour values of the geopotential perturbation field (in $\mathrm{m}^{2} \mathrm{sec}^{-2}$ ) are $-550,-350,-150,20,60$ and 100.

India for various strengths and latitudinal position of the heat sink. The above model though successful in producing moderate southward displacement of the mid-tropospheric ridge has its limitations. It is known that the mid-tropospheric ridge seen over India has equatorward tilt with height. Also for the same amount of excess snow cover over Eurasia in preceding winter/spring the southward displacement of the $500 \mathrm{hPa}$ ridge over India could be different for two different years. This brings to the fore the importance of the role of the background flow on the southward displacement of the $500 \mathrm{hPa}$ ridge. Hence there is a real need to incorporate the background (mean) flow and study its effect on the southward displacement of the $500 \mathrm{hPa}$ ridge. Also it would be of interest to study the role of the nonlinear advective terms on the southward displacement of the $500 \mathrm{hPa}$ ridge.

\section{Conclusions}

A linear model of the steady response of a stratified fluid to heat sources in spherical coordinates is used to study the mid-tropospheric ridge. By prescribing a heat sink north of the heat sources, we have successfully demonstrated significant southward displacement of the $500 \mathrm{hPa}$ ridge. The results of the sensitivity study of the strength and the position of the heat sink on the southward displacement of the $500 \mathrm{hPa}$ ridge indicate that the strength of the heat sink has more effect on the southward displacement of the $500 \mathrm{hPa}$ ridge when the heat sink is at a lower latitude. Also the results of this study indicate that the latitudinal position of the sink has an important effect on the southward displacement of the $500 \mathrm{hPa}$ ridge only for the case where the 


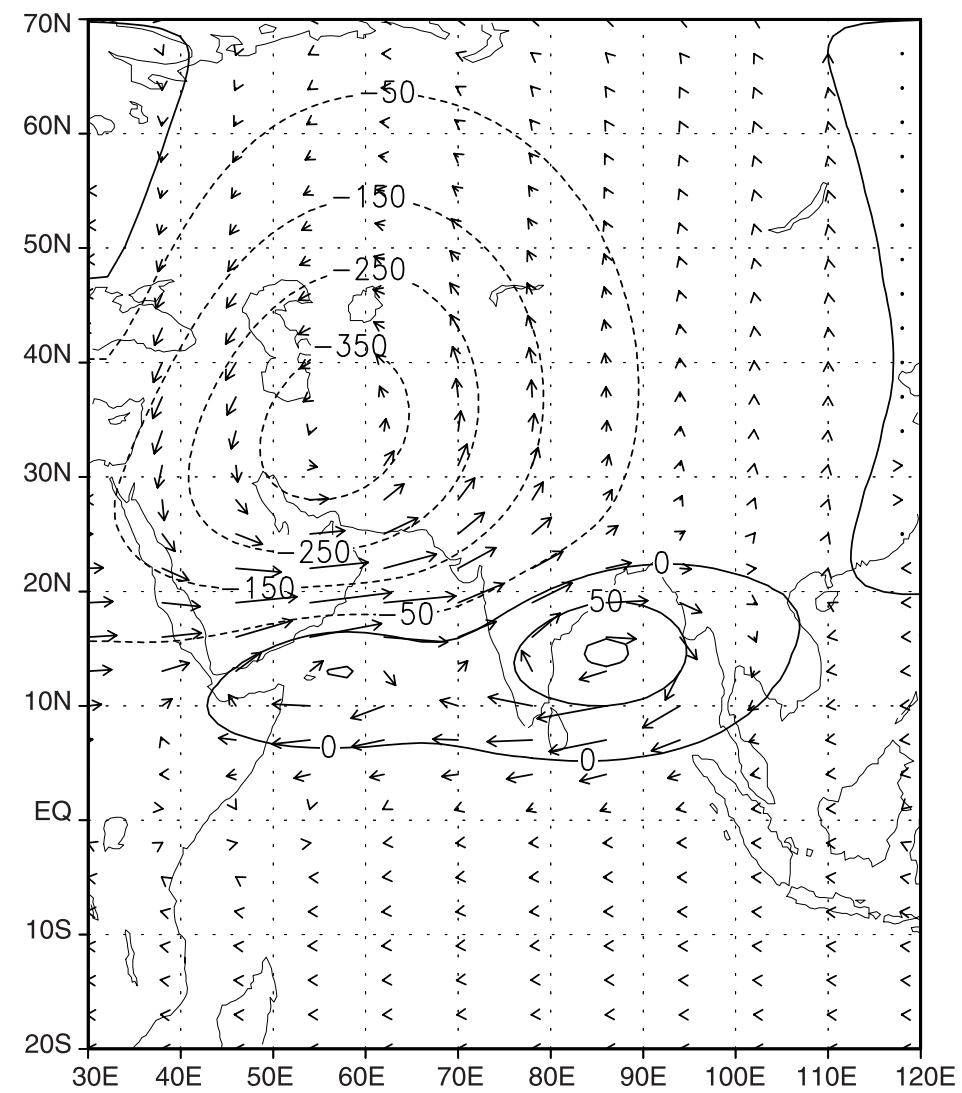

Figure 13. Same as figure 11 except that the vertically integrated cooling rate is $-1^{\circ} \mathrm{C} \mathrm{day}{ }^{-1}$. Contour values of the geopotential perturbation field $\left(\right.$ in $\mathrm{m}^{2} \mathrm{sec}^{-2}$ ) are $-350,-250,-150,-50,0,50$ and 100 .

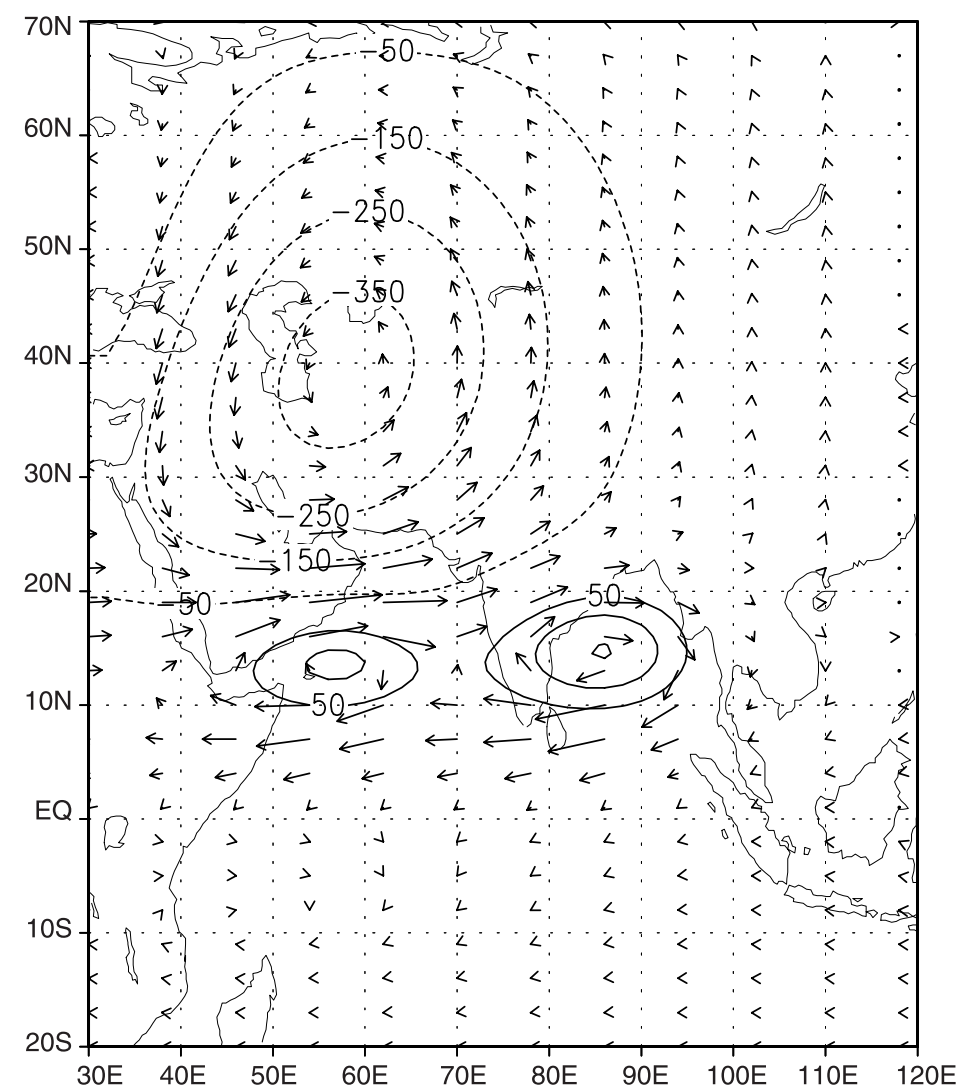

Figure 14. Same as figure 12 except that the vertically integrated cooling rate is $-1^{\circ} \mathrm{C}$ day ${ }^{-1}$. Contour values of the geopotential perturbation field $\left(\mathrm{in}^{2} \mathrm{sec}^{-2}\right.$ ) are $-350,-250,-150,-50,50,80$ and 110 . 
Table 1. Southward displacement of the 500 hPa ridge.

\begin{tabular}{lccr}
\hline & \multicolumn{3}{c}{ Position of sink } \\
\cline { 2 - 4 } Cooling rate & $34^{\circ} \mathrm{N}$ & $40^{\circ} \mathrm{N}$ & $46^{\circ} \mathrm{N}$ \\
\hline$-2^{\circ} \mathrm{C} \mathrm{day}^{-1}$ & $500 \mathrm{~km}$ & $291 \mathrm{~km}$ & $125 \mathrm{~km}$ \\
$-1.5^{\circ} \mathrm{C} \mathrm{day}^{-1}$ & $374 \mathrm{~km}$ & $208 \mathrm{~km}$ & $125 \mathrm{~km}$ \\
$-1^{\circ} \mathrm{C}$ day $^{-1}$ & $208 \mathrm{~km}$ & $125 \mathrm{~km}$ & $83 \mathrm{~km}$ \\
\hline
\end{tabular}

vertical cooling associated with the heat sink is strongest.

\section{Acknowledgement}

The author is grateful to the Department of Science and Technology, Government of India for partial support for this work. All the figures in this study have been made using the GrADS provided by COLA. The author acknowledges Mr R K Sahoo for his help in the initial development of the code. The author thanks Prof B N Goswami for his encouragement and advice. The author also thanks the anonymous referees for their pertinent and constructive comments which have helped improve the manuscript considerably.

\section{References}

Bamzai A S and Shukla J 1999 Relation between Eurasian snow cover, snow depth and the Indian summer monsoon: An observational study; J. Climate 12 3117-3132

Banerjee A K, Sen P N and Raman C R V 1978 On foreshadowing southwest monsoon rainfall over India with mid-tropospheric circulation anomaly of April; Indian J. Met. Geophys. 29 425-431

Barnett T P, Diimenil L, Schlese V, Roeckner E and Latif M 1989 The effect of Eurasian snow cover on regional and global climate variations; J. Atmos. Sci. 46 661-685

Bhanukumar O S R U 1988a Interaction between Eurasian winter snow cover and location of the ridge at the
$500 \mathrm{hPa}$ level along $75^{\circ} \mathrm{E} ;$ J. Meteor. Soc. Japan 66 509-514

Bhanukumar O S R U 1988b Eurasian snow cover and seasonal forecast of Indian summer monsoon rainfall; J. Hydrol. Sci. 35 515-525

Blanford H F 1884 On the connection of the Himalayan snow with dry winds and seasons of droughts in India; Proc. R. Soc. London 37 3-22

Chandrasekar A and Goswami B N 1996 A linear model study of the mid-tropospheric ridge and its displacement; Mausam 47 369-376

Chandrasekar A 1997 A linear model study of the midtropospheric ridge and its displacement - Inclusion of a surface heat sink; Mausam 48 29-32

Dey B and Bhanukumar O S R U 1982 An apparent relationship between Eurasian spring snow cover and advance period of the Indian summer monsoon; J. Appl. Meteorol. 21 1929-1932

Hahn D and Shukla J 1976 An apparent relationship between European snow cover and Indian monsoon rainfall; J. Atmos. Sci. 33 2461-2463

Mooley D A, Parthasarathy B and Pant G B 1986 Relationship between Indian summer monsoon rainfall and location of the ridge at the $500 \mathrm{mb}$ level along $75^{\circ} \mathrm{E} ; \mathrm{J}$. Clim. Appl. Met. 25 633-640

Lindzen R S and Kuo H L 1969 A reliable method for the numerical integration of a large class of ordinary and partial differential equations; Mon. Weather Rev. 97 732-734

Sashegyi K D and Geisler J E 1987 A linear model study of the cross equatorial flow forced by summer monsoon heat sources; J. Atmos. Sci. 44 1706-1722

Shukla J and Mooley D A 1987 Empirical prediction of the summer monsoon rainfall over India; Mon. Weather Rev. 115 695-703

Verma R K 1980 Importance of the upper tropospheric thermal anomalies for long range forecasting in Indian summer monsoon activity; Mon. Weather Rev. 108 10721075

Vernekar A D, Zhou J and Shukla J 1995 The effect of Eurasian snow cover on the Indian monsoon; J. Climate $8248-266$

Yasunari T, Kitoh A and Tokioka T 1991 Local and remote responses to excessive snow mass over Eurasia appearing in the northern spring and summer climate - a study with the MRI GCM; J. Meteor. Soc. Japan 69 473-487 